\title{
Fragmentation of Conjugate Bases of Esters Derived from Multifunctional Alcohols Including Triacylglycerols*
}

\author{
Vincent Stroobant, Raoul Rozenberg, el Mounir Bouabsa, Etienne \\ Deffense, and Edmond de Hoffmann \\ Université Catholique de Louvain, Service de Spectrométrie de Masse, Louvain-la-Neuve, Belgium
}

\begin{abstract}
Enolate anions of esters from 1,2 and 1,3 diols undergo an internal nucleophilic substitution reaction that produces a $\beta$-ketoester and an alkoxide ion within the molecular species. These intermediate ions undergo two competitive fragmentation pathways. The first pathway corresponds to a second nucleophilic substitution of the ketoester by the alkoxide that yields a neutral cyclic ether and the $\beta$-ketoacid carboxylate. The latter then loses carbon dioxide and produces the enolate anion of the corresponding ketone. The second proposed pathway is stepwise: it starts with a proton transfer from the methylene group between the two carbonyls to the alkoxide anion that produces an alcohol and the enolate ion of the $\beta$-ketoester inside the molecular species. The latter undergoes cleavage of the ester bond induced by the negative charge to yield an ion-dipole complex composed of a neutral acylketene and an alkoxide ion. The direct dissociation of this ion-dipole complex competes with an internal proton exchange to yield a new complex that consists of an alcohol molecule and the anion of the acylketene, which can also dissociate. The fragmentation pathway that leads to the ketone enolate is sensitive to the relative positions $(1,2$ or 1,3$)$ of the esters on the molecular backbone. This position-sensitive reaction is useful for the assignment of the primary and secondary positions in triacylglycerols, even in mixtures, as shown by some examples. (J Am Soc Mass Spectrom 1995, 6, 498-506)
\end{abstract}

$\mathrm{N}$ egative ion fragmentations in the gas phase have not been studied as extensively as fragmentations of positive ions. The advent of ionization techniques that produce negative ions, mainly chemical ionization ( $\mathrm{CI})$ and fast-atom bombardment (FAB), together with the development of efficient detectors that use a conversion dynode, have favored such studies [1]. Even-electron negative ions can be obtained by the formation of an adduct between an anion $\left(\mathrm{Cl}^{-}\right.$for example) and a molecule, or more often by proton abstraction with an appropriate base. The main rule that underlies this latter ionization is that to be efficient, the proton abstraction has to be exothermic [2]. The last important reviews on the topic of even-electron negative ion fragmentation were published by Bowie in 1990 [3] and 1994 [4].

No studies on the fragmentation under low energy collision-induced dissociation (CID) of ester anions from multifunctional alcohols have been reported in the literature. However, triglycerides belong to this

Address reprint requests to Vincent Stroobant, Spectrométrie de Masse, Place Pasteur 1, 1348 Louvain-la-Neuve, Belgium.

- This paper is dedicated to Professor Heinz Viehe, on the occasion of his 65th birthday and to Professor Léon Ghosez on the occasion of his 60th birthday. class of compounds, and collision-induced dissociation of their anions has important analytical applications [5, 6]. Several fragments are of unknown origin and are designated empirically as $[\mathrm{M}-\mathrm{H}-\mathrm{x}]^{-}$, where $x$ represents the mass of a frequently lost unknown neutral.

In this article we report a systematic study of this fragmentation that uses esters of ethyleneglycol, 1,3propanediol, and triglycerides. All the low energy CID fragmentation routes of these anions are explained.

\section{Experimental}

\section{Materials}

Ethyleneglycol diacetate was obtained from Aldrich Chemical Co. (Milwaukee, WI). The 1,3-propanediol diacetate and dipropionate, the ethyleneglycol dipropionate, and the ethyleneglycol monoacetoacetate were synthesized as described elsewhere [7]. The 1,3dipalmitoyl-2-oleoyl-glycerol (16:0/18:1, [cis]-9/16:0) and the 1,2-dipalmitoyl-3-oleoyl-rac-glycerol (16:0/16:0/18:1, [cis]-9) were purchased from Sigma Chemical Co. (St. Louis, MO) and used without further purification. The natural cocoa butter sample was provided by Tirtiaux Fractionement S.A. (Fleurus, Belgium). 


\section{Mass Spectrometry}

Desorption chemical ionization (DCI) experiments were carried out on a TSQ 70 triple stage quadrupole instrument from Finnigan MAT (San Jose, CA). The chemical ionization source was operated at 9 torr with a $75 / 25$ $\mathrm{v} / \mathrm{v}$ mixture of $\mathrm{CH}_{4} / \mathrm{N}_{2} \mathrm{O}$ that was purchased from Air Liquide (Liege, Belgium). The ionization was obtained by a $200 \mu \mathrm{A}$ and $70 \mathrm{eV}$ electron beam. The ion source was kept at $150{ }^{\circ} \mathrm{C}$ for the diesters and $230^{\circ} \mathrm{C}$ for the triacylglycerols. A small quantity of the sample solution was placed with a syringe onto the DCI emitter. After evaporation of the solvent, the probe was directly introduced into the ion source of the mass spectrometer and the wire was then heated.

CID fragmentations of the $[\mathrm{M}-\mathrm{H}]^{-}$ion were performed with $\mathrm{Xe}$ at $0.8 \mathrm{mtorr}$ in the rf-only quadrupole collision cell with a collision offset voltage between 0 and $6 \mathrm{~V}$ for the diesters and $0.5 \mathrm{~V}$ for the triacylglycerols.

The elemental compositions of the fragments were determined by using a previously described method [8]. Briefly, if an isotopic peak of the parent ion is selected, there will be a statistical distribution of the isotopes in the fragments. These distributions can be used to assign the number of atoms that correspond to the selected isotope present in the fragment.

\section{Results and Discussion}

\section{Structures of the Fragment Ions}

The negative ion DCI spectra of the esters of the 1,2-ethanediol diacetate and dipropionate and of 1,3- propanediol diacetate and dipropionate show prominent $[\mathrm{M}-\mathrm{H}]^{-}$ions (spectra not shown). Except for an abundant fragment that corresponds to the anion of the carboxylic acid, very little fragmentation is observed. In contrast, the low energy CID fragmentation spectra of the $[\mathrm{M}-\mathrm{H}]^{-}$ions of these compounds display abundant fragments as shown in Figure 1. These fragmentations already are observed at very low collision energy, even at less than $1 \mathrm{~V}$ offset voltage. The interpretation of the fragmentation pathways of these compounds is not straightforward. The elementary compositions of the fragments have been determined by using a method based on the comparison of the fragmentation spectra from ions selected from the isotopic cluster of the parent ion as described in the materials section. The results obtained for the fragments with the help of this method are shown in Table 1.

Because the studied diol ester compounds contain homologous substructures in either the diol or carboxylic acid moiety, a comparison of the spectra of these compounds gives information about the nature of the fragments.

Whereas ethyleneglycol diacetate and 1,3-propanediol diacetate differ only by a methylene group $\left(\mathrm{CH}_{2}\right)$ in the diol moiety, every $14 \mathrm{u}$ peak shift contains this moiety. For the same reason, every peak in the spectrum of the 1,3-propanediol diacetate shifted by 14 or $28 \mathrm{u}$ in the spectrum of the 1,3-propanediol dipropionate contains, respectively, one or two carboxylic acids. For instance, observation of fragment ions at $m / z 83,111,83$, and 111 , respectively, in the spectra of ethyleneglycol diacetate and dipropionate, 1,3-propan-
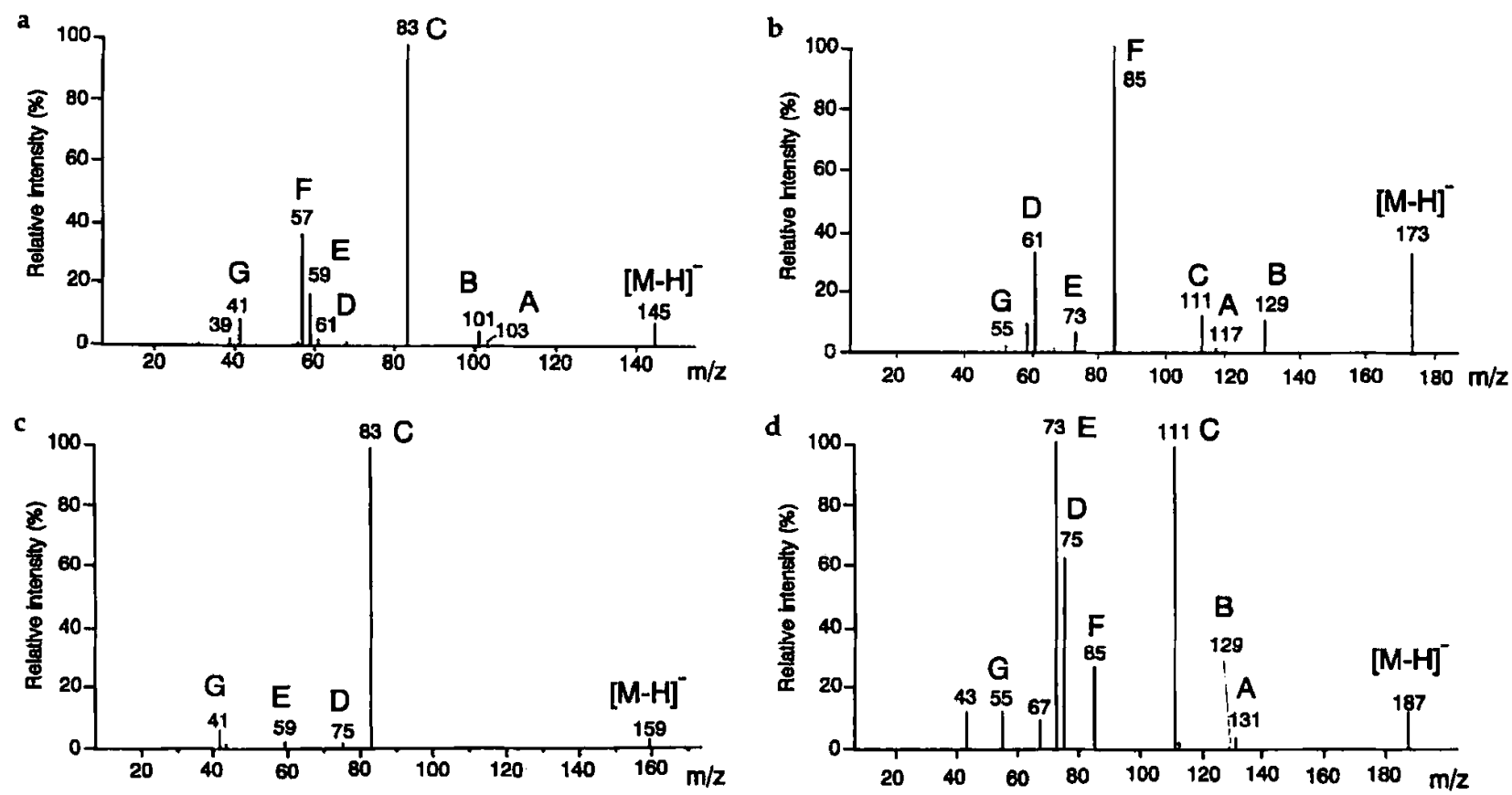

Figure 1. CID negative ion fragment spectra of $[\mathrm{M}-\mathrm{H}]^{-}$at $3 \mathrm{~V}$ collision offset voltage of (a) ethyleneglycol diacetate, (b) ethyleneglycol dipropionate, (c) 1,3-propanediol diacetate, and (d) 1,3-propanediol dipropionate. The capital letters correspond to the symbols that characterize each of the fragments represented in Table 2. 
ediol diacetate, and dipropionate (Figure 1a-d) implies formation of a common fragment that contains the two carboxylic acid chains but not the diol moiety. All the information deduced from these comparisons is presented in Table 2.

\section{Gas-Phase Rearrangement of the Molecular Species}

From these structures the resulting main fragmentation pathways are deduced. They are displayed in Scheme I. The main observed fragments can be explained as the result of the formation in the first step of an internal $\beta$-ketoester by a new gas-phase rearrangement of these enolate anions. This rearrangement logically results from an intramolecular nucleophilic substitution reaction, where the enolic carbanion is the nucleophile (Scheme I, path a). Such nucleophilic substitutions have been observed already in the gas phase in intermolecular Claisen reactions of esters [9] and in intramolecular Dieckman cyclization of the dimethyl ester of adipic acid, as shown in Scheme II [10]. For this last reaction, both an intermediate ion dipole complex and a concerted mechanism have been invoked $[10,11]$.

Enolate anions have an ambident behavior because reactions through both the carbanion or the oxanion sites as nucleophiles are possible. One case of gas-phase oxanion nucleophilic reaction has been reported [12]. In the present study, no detectable fragment characteristic of a reaction of the enolate anions by the oxanion site has been identified. This also was observed by Bartmess et al. [9] for intermolecular Claisen condensations.

To verify the proposed rearrangement step in this fragmentation pathway, ethyleneglycol monoacetoac- etate, a compound that corresponds to the postulated intermediate for the ethyleneglycol diacetate fragmentation, has been synthesized. An almost identical spectrum is observed for the CID tandem mass spectrometry fragmentation of the anions of these two compounds. This not only demonstrates that ethyleneglycol monoacetoacetate anion is indeed the intermediate, but also that its formation is reversible.

Thus, it appears that both ethyleneglycol and 1,3propylenediol esters undergo the same intramolecular rearrangement through a nucleophilic substitution to obtain ions that contain a $\beta$-ketoester and an alkoxide ion inside the molecular species. However, the fate of this rearranged anion depends on the two competitive fragmentation pathways that lead to the ketone enolate (Scheme I, pathway b) or the acylketene anion (Scheme $\mathrm{I}$, pathway $\mathrm{b}^{\prime}$ ), and is different for these diol esters.

\section{Formation of Ketone Enolate Fragment}

The first pathway corresponds to a second nucleophilic substitution of the ketoester by the alkoxide (Scheme I, path b) that yields a neutral cyclic ether and the $\beta$-ketoacid carboxylate (Scheme I, formula B), an ion often observed in the spectra but at low intensities. The $\beta$-ketoacid carboxylate anion then loses carbon dioxide and produces the enolate anion of the corresponding ketone (Scheme I, pathway c, formula F). This fragment ion is always observed. It is important for the diol diesters, except for 1,3-propanediol diacetate (Figure 1a-d, formula F), and very important, as will be seen later on, in triglycerides.

The fragmentation pathway that leads to the ketone enolate (Scheme I, pathway $b$ ) is sensitive to the relative positions $(1,2$ or 1,3$)$ of the esters on the molecular

Table 1. Determination of the elemental compositions of the fragments from ethyleneglycol diacetate as an example ${ }^{a}$

\begin{tabular}{|c|c|c|c|c|c|c|c|c|}
\hline & {$[\mathrm{M}-\mathrm{H}]^{-}$} & $\bar{A}$ & B & C & D & $\bar{E}$ & $F$ & $\bar{G}$ \\
\hline $\begin{array}{r}\text { Masses } \\
(\mathrm{m} / \mathrm{z})\end{array}$ & 145 & 103 & 101 & 83 & 61 & 59 & 57 & 41 \\
\hline $\begin{array}{l}\text { Possible } \\
\text { formulas }\end{array}$ & $\mathrm{C}_{6} \mathrm{H}_{10} \mathrm{O}_{4}$ & $\begin{array}{l}\mathrm{C}_{3} \mathrm{H}_{3} \mathrm{O}_{4} \\
\mathrm{C}_{4} \mathrm{H}_{7} \mathrm{O}_{3} \\
\mathrm{C}_{5} \mathrm{H}_{11} \mathrm{O}_{2}\end{array}$ & $\begin{array}{l}\mathrm{C}_{3} \mathrm{HO}_{4} \\
\mathrm{C}_{4} \mathrm{H}_{5} \mathrm{O}_{3} \\
\mathrm{C}_{5} \mathrm{H}_{9} \mathrm{O}_{2}\end{array}$ & $\begin{array}{c}\mathrm{C}_{4} \mathrm{H}_{3} \mathrm{O}_{2} \\
\mathrm{C}_{5} \mathrm{H}_{7} \mathrm{O}\end{array}$ & $\begin{array}{c}\mathrm{CHO}_{3} \\
\mathrm{C}_{2} \mathrm{H}_{5} \mathrm{O}_{2} \\
\mathrm{C}_{5} \mathrm{H}\end{array}$ & $\begin{array}{c}\mathrm{C}_{2} \mathrm{H}_{3} \mathrm{O}_{2} \\
\mathrm{C}_{3} \mathrm{H}_{7} \mathrm{O}\end{array}$ & $\begin{array}{c}\mathrm{C}_{4} \mathrm{H}_{9} \\
\mathrm{C}_{3} \mathrm{H}_{5} \mathrm{O} \\
\mathrm{C}_{2} \mathrm{HO}_{2}\end{array}$ & $\begin{array}{l}\mathrm{C}_{2} \mathrm{HO} \\
\mathrm{C}_{3} \mathrm{H}_{5}\end{array}$ \\
\hline $\begin{array}{c}\text { Isotopic } \\
\text { masses } \\
(\mathrm{m} / \mathrm{z})\end{array}$ & 146 & $104 / 103$ & $102 / 101$ & $84 / 83$ & $62 / 61$ & $60 / 59$ & $58 / 57$ & $42 / 41$ \\
\hline $\begin{array}{l}\text { Intensities } \\
\text { ratios }\end{array}$ & - & $2 / 1$ & $2 / 1$ & $2 / 1$ & $1 / 2$ & $1 / 2$ & $1 / 1$ & $1 / 2$ \\
\hline $\begin{array}{l}\text { Number of } \\
\text { carbon } \\
\text { atoms }\end{array}$ & - & 4 & 4 & 4 & 2 & 2 & 3 & 2 \\
\hline Formula & $\mathrm{C}_{6} \mathrm{H}_{10} \mathrm{O}_{4}$ & $\mathrm{C}_{4} \mathrm{H}_{7} \mathrm{O}_{3}$ & $\mathrm{C}_{4} \mathrm{H}_{5} \mathrm{O}_{3}$ & $\mathrm{C}_{4} \mathrm{H}_{3} \mathrm{O}_{2}$ & $\mathrm{C}_{2} \mathrm{H}_{5} \mathrm{O}_{2}$ & $\mathrm{C}_{2} \mathrm{H}_{3} \mathrm{O}_{2}$ & $\mathrm{C}_{3} \mathrm{H}_{5} \mathrm{O}$ & $\mathrm{C}_{2} \mathrm{HO}$ \\
\hline
\end{tabular}

\footnotetext{
"Knowing the elemental composition of the parent ion, the possible elemental compositions of each fragment ion can be determined. If the $[M+1]$ isotopic peak $(m / z 146$ instead of 145) is selected as the parent ion, the fragment ions appear as doublets, as shown in the row Isotopic masses. From the relative intensities in the doublets, the number of carbon atoms in the fragment can be determined [8].
} 
Table 2. From a combination of the information from elemental composition (Table 1) and from comparisons of the spectra of the different diols esters, the structures of the fragments are deduced. The symbols and the names used in this paper are given in the first and last columns, respectively

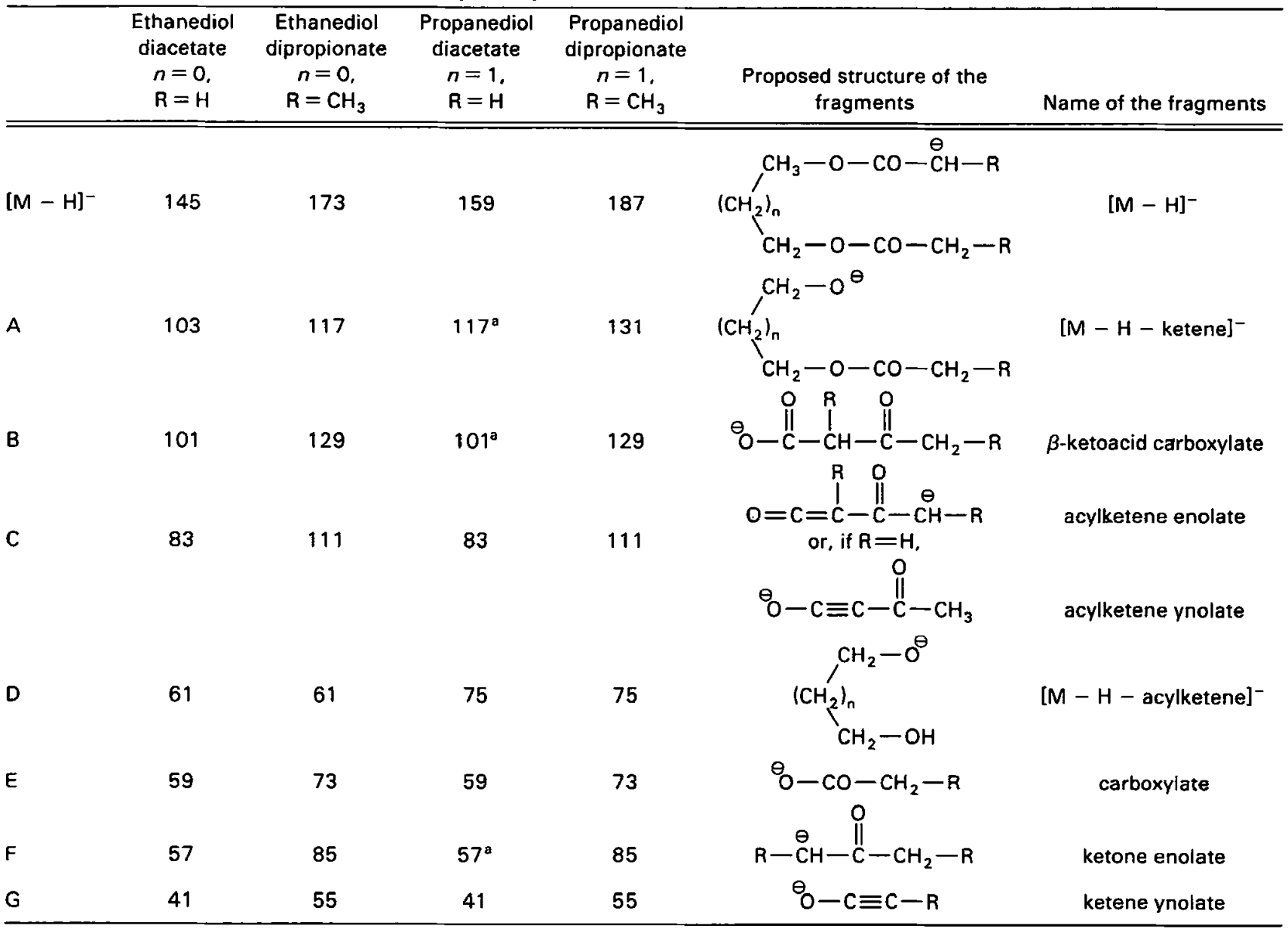

a Fragment ions not observed in the spectra of Figure 1, but detected at trace levels or at another collision offset voltage.

backbone. This sensitivity is established by comparison of the product ion spectra from the $[\mathrm{M}-\mathrm{H}]^{-}$ion of 1,2-ethanediol diacetate (Figure 1a) and 1,3-propanediol diacetate (Figure 1c) or by comparison of the spectra of 1,2-ethanediol dipropionate (Figure $1 \mathrm{~b}$ ) and 1,3-propanediol dipropionate (Figure 1d). The spectra of 1,3-propanediol esters show a drastic decrease of the ketone enolate (formula F). A reason for this could be that the expulsion of the $\beta$-ketoacid anion to form a neutral epoxide is much faster than the expulsion that would lead to an oxetane neutral, as is described for intramolecular nucleophilic substitution in the condensed phase [13]. Thus, the formation of the ketone enolate is favored by a vicinal ester position. This position-sensitive reaction appears to be very useful in triacylglycerol primary or secondary ester position assignment, as shown below.

\section{Formation of Acylketene Fragment as Anion or Neutral Species}

The second proposed pathway is stepwise. It starts with a proton transfer from the methylene group be- tween the two carbonyls to the alkoxide anion, which produces an alcohol and the enolate ion of the $\beta$ ketoester inside the molecular species (Scheme I, pathway $b^{\prime}$ ). The latter undergoes the cleavage of the ester bond induced by the negative charge to yield an ion-dipole complex composed of a neutral acylketene and an alkoxide ion (Scheme I, pathway d). Some ions separate at this stage, and the alkoxide anion is observed in the spectrum (Scheme I, pathway $\mathrm{f}$, formula D). This direct dissociation of this ion-dipole complex competes with a proton exchange inside the complex (Scheme I, pathway e) that yields a new complex composed of an alcohol molecule and the anion of the acylketene. This new complex also can dissociate to yield the ynolate of the acylketene for the acetate ester (Scheme III, pathway $g^{\prime}$, formula C) or the enolate of the acylketene for the other esters (Scheme I, pathway $\mathrm{g}$, formula C).

The first proton migration can be explained by considering that the acidity that characterizes the alkoxide anion (for $\mathrm{CH}_{3} \mathrm{CH}_{2} \mathrm{OH}, \Delta G_{\text {acid }}=1548 \mathrm{~kJ} / \mathrm{mol}$ ) is lower than the acidity that characterizes the enolate ion of the $\beta$-ketoester (for $\mathrm{CH}_{3} \mathrm{COCH}_{2} \mathrm{COCH}_{3}, \Delta G_{\text {acid }}=1409$ 


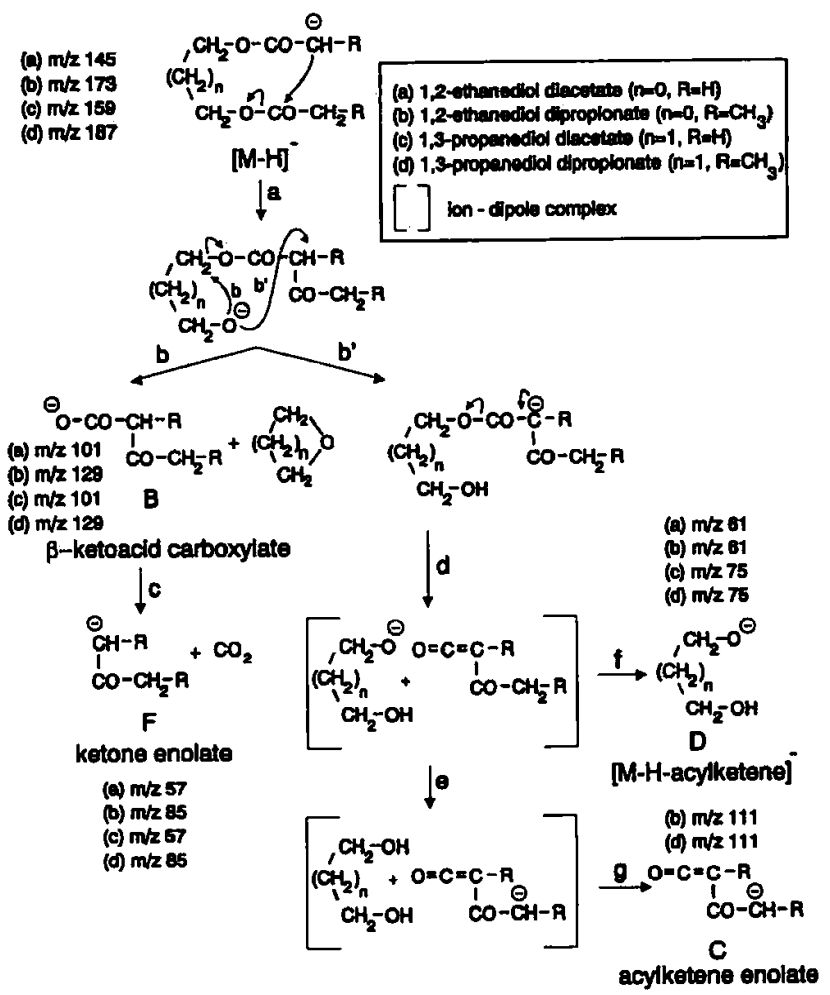

Scheme I

$\mathrm{kJ} / \mathrm{mol}$ ), as judged from the indicated values for related compounds [14]. Thus, this proton transfer from the $\beta$-ketoester neutral moiety to the alkoxide moiety (Scheme I, pathway b'), which yields the intermediate, is favored both kinetically and thermodynamically by its exothermic character [2].

Similarly, the orientation of the second proton transfer between the two moieties of the ion-dipole complex (Scheme I, pathway e) is influenced by the relative acidities of these two moieties. The alcohol acidity (for $\mathrm{CH}_{3} \mathrm{CH}_{2} \mathrm{OH}, \Delta \mathrm{G}_{\text {acid }}=1548 \mathrm{~kJ} / \mathrm{mol}$ ) must be compared with that of the ynolate of the acylketene for the acetate ester (for $\mathrm{CH}_{2} \mathrm{CO}, \Delta G_{\text {acid }}=1497 \mathrm{~kJ} / \mathrm{mol}$; this value should be lower for an acylketene) or the enolate of the acylketene for the other esters (for $\mathrm{CH}_{3} \mathrm{COCH}_{3}$, $\Delta G_{\text {acid }}=1514 \mathrm{~kJ} / \mathrm{mol}$ ).

Such ion-dipole complexes previously have been proposed to explain the fragmentation in similar cases $[10,15,16]$. The above-mentioned cyclization of adipic acid (Scheme II) is one example. Fragmentations that involve ketene loss have been observed in several other acid and ester fragmentations. Formation of ketene anions by reionization through an ion-molecule dipole also has been reported, as shown, for example, in Scheme IV [16].

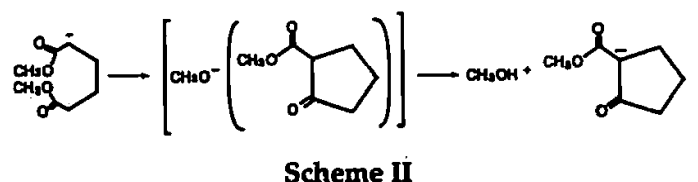

Scheme II

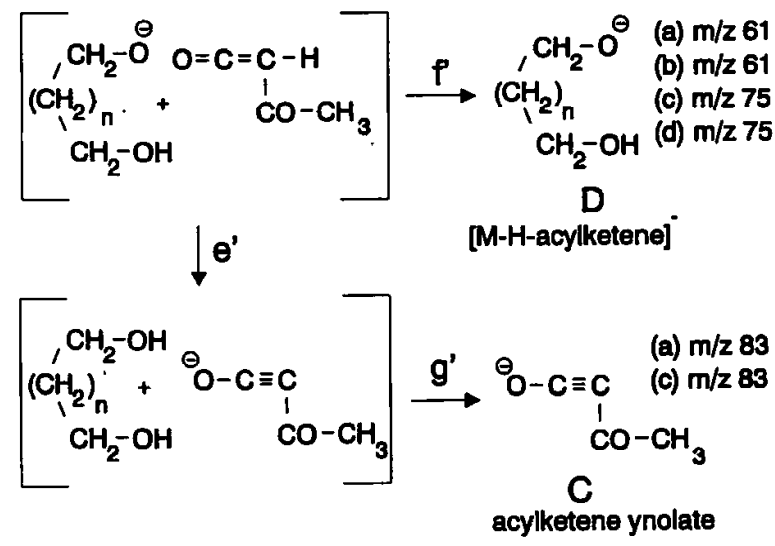

Scheme III

Ion-dipole complexes should only be important for low energy reactions, and should be favored at low collision energy [17]. These criteria apply to the complexes reported here. Indeed, the corresponding fragments are not observed in the DCI spectrum. Furthermore, a comparison of the product ion spectra from the deprotonated anion of 1,3-propanediol dipropionate (Table 3) at 1,3 , and $6 \mathrm{~V}$ collision offset voltages, respectively, shows a decrease of fragment $C$ and an increase of the complementary fragment $D$ at higher energy (Scheme I). At low energy, the ion-dipole complex has a sufficient lifetime to allow reaction e (Scheme I) and thus fragment $C$ is observed. At higher energy, this complex dissociates to yield fragment $D$.

The fragmentation pathway that leads to the acylketene anion (Scheme I, pathway $b^{\prime}$ ) is influenced by the presence of an alkyl group on the methylene group between the two carbonyls of the intermediate. This is established by comparison of the product ion spectra from the deprotonated anion of 1,2-propanediol diacetate (Figure 1a) and 1,2-propanediol dipropionate (Figure $1 \mathrm{~b}$ ) and by comparison of spectra of 1,3-propanediol diacetate (Figure 1c) and 1,3-propanediol dipropionate (Figure 1d), which show a decrease of the ratio of the anion abundance of the acylketene (formula C) to the ketone (formula F). A reason for this could be that the presence of an alkyl group increases the steric hindrance at the methylene group between the two carbonyls. It becomes more difficult for the alkoxide anion to transfer a proton and thus, the rate of this reaction diminishes. Switching from esters of diols to triacylglycerols, where the akyl group corresponds to a long and bulky hydrocarbon chain, the acylketene enolates almost disappear to become minor fragments (as demonstrated in Figure 3).

\section{Application to Triacylglycerols}

Because the fragmentation pathway that leads to the ketone enolate is sensitive to the relative positions $(1,2$

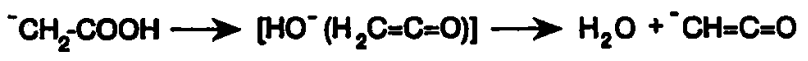


Table 3. Relative intensities of the acylketene enolate fragment (formula $\mathrm{C}$ ) and its complementary fragment (formula D) in the product ion spectra from the deprotonated 1,3-propanediol dipropionate at 1,3, and $6 \mathrm{~V}$ collision offset voltage

\begin{tabular}{lcccc}
\hline & & \multicolumn{3}{c}{ Relative intensities at collision offset voltage } \\
\cline { 2 - 5 } & Masses $(m / z)$ & $1 \mathrm{~V}$ & $3 \mathrm{~V}$ & $6 \mathrm{~V}$ \\
\hline \hline $\mathrm{M}-\mathrm{H}^{-}$ & 187 & 100 & 14 & 5 \\
$\mathrm{C}$ & 111 & 59 & 100 & 8 \\
$\mathrm{D}$ & 75 & 16 & 60 & 100 \\
\hline
\end{tabular}

or 1,3$)$ of the esters on the molecular backbone and is favored by longer chain fatty acids, this fragment ion appears to be very useful in triacylglycerol primary or secondary ester position assignment, as shown in the following text.

The negative DCI mass spectra of triacylglycerols also are characterized by an abundant $[\mathrm{M}-\mathrm{H}]^{-}$ion and the corresponding fatty acid ions $\mathrm{R} 1 \mathrm{COO}^{-}$, $\mathrm{R}_{2} \mathrm{COO}^{-}$, and $\mathrm{R}_{3} \mathrm{COO}^{-}$. Figure 2 shows as an example the DCI spectrum of 1,3-dipalmitoyl-2-oleoylglycerol (POP). In this spectrum, the deprotonated anion at $\mathrm{m} / \mathrm{z} 831$ and the corresponding palmitate and oleate ions, respectively, at $\mathrm{m} / \mathrm{z} 255$ and 281 , are observed. This fragmentation is analytically useful to determine the composition, but not the structure of triacylglycerol. However, it can be applied only to pure compounds.

The low energy CID fragmentation spectra of the $[\mathrm{M}-\mathrm{H}]^{-}$ions of triacylglycerols are characterized by four series of ions: $\left[\mathrm{M}-\mathrm{H}-\mathrm{R} n \mathrm{CO}_{2} \mathrm{H}\right]^{-},[\mathrm{M}-\mathrm{H}-$ $\left.\mathrm{R} n \mathrm{CO}_{2} \mathrm{H}-74\right]^{-}, \quad\left[\mathrm{M}-\mathrm{H}-\mathrm{R} n \mathrm{CO}_{2} \mathrm{H}-100\right]^{-}$, and $\mathrm{R}_{n} \mathrm{CO}_{2}^{-}[5,6]$. Indeed, at low energy, the $[\mathrm{M}-\mathrm{H}-$ $\left.\mathrm{R} n \mathrm{CO}_{2} \mathrm{H}\right]^{-}$and $\left[\mathrm{M}-\mathrm{H}-\mathrm{R} n \mathrm{CO}_{2} \mathrm{H}-74\right]^{-}$ions are minor fragmentations in comparison to the fragmentations that lead to the fragments $\left[\mathrm{M}-\mathrm{H}-\mathrm{R} n \mathrm{CO}_{2} \mathrm{H}-\right.$ $100]^{-}$and $\mathrm{R} n \mathrm{CO}_{2}^{-}$ions. This is illustrated in Figure 3, which shows the fragmentation spectra of the $[M-$ $\mathrm{H}]^{-}$ions of 1,3-dipalmitoyl-2-oleoyl-glycerol (POP) and 1,2-dipalmitoyl-3-oleoyl-rac-glycerol (PPO), two positional isomers. As in the DCI spectra, the presence of the fatty acid ions gives information about the compo-

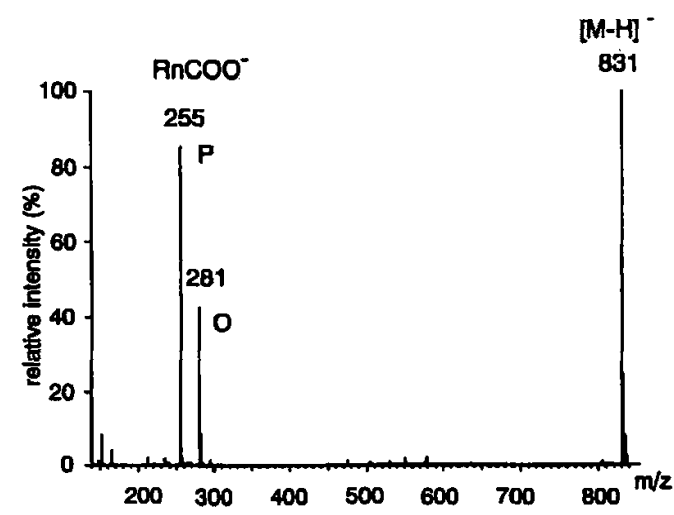

Figure 2. DCI spectrum of POP triglyceride with peaks at $m / z$ 831,281 , and 255 , that correspond, respectively, to the $[\mathrm{M}-\mathrm{H}]^{-}$ ion, the oleic carboxylate anion $(\mathrm{O})$, and the palmitic carboxylate anion (P). sition of the corresponding triacylglycerols, but it is now applicable also to mixtures.

From the mechanism described in the preceding text, the origins and features of the $[\mathrm{M}-\mathrm{H}-$ $\left.\mathrm{R} n \mathrm{CO}_{2} \mathrm{H}-74\right]^{-}$and $\left[\mathrm{M}-\mathrm{H}-\mathrm{R}_{n} \mathrm{CO}_{2} \mathrm{H}-100\right]^{-}$ ions can now be explained: they correspond to the acylketene enolate and the ketone enolate, respectively, observed in the fragmentation spectra of the esters of diol compounds, as shown in Scheme V.

As previously described, the reaction that leads to the formation of ketone enolate is sensitive to the position of the fatty acids. This is confirmed in the
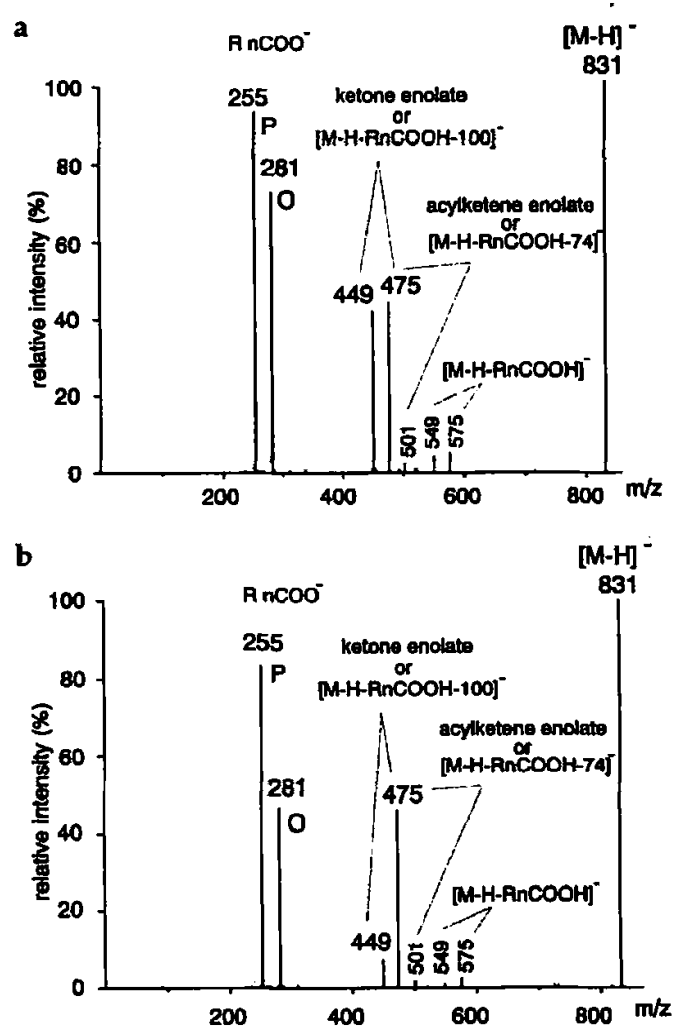

Figure 3. Fragmentation spectra of the $[\mathrm{M}-\mathrm{H}]^{-}$ions of the (a) PPO and (b) POP triglycerides at $0.5-\mathrm{eV}$ collisional energy (average of 10 scans). In addition to the $\left[\mathrm{M}-\mathrm{H}^{-}\right.$ion, four series of ions $\left[\mathrm{M}-\mathrm{H}-\mathrm{RnCO}_{2} \mathrm{H}\right]^{-},\left[\mathrm{M}-\mathrm{H}-\mathrm{R} n \mathrm{CO}_{2} \mathrm{H}-74\right]^{-},[\mathrm{M}-$ $\left.\mathrm{H}-\mathrm{R} n \mathrm{CO}_{2} \mathrm{H}-100\right]^{-}$, and $\mathrm{RnCO}_{2}^{-}$have been observed. Because the difference between the masses of oleic and palmitic acids is $26 \mathrm{u}$, one of the two $\left[\mathrm{M}-\mathrm{H}-\mathrm{RnCO}_{2} \mathrm{H}-74\right]^{-}$ions is detected at the same value $(m / z 475)$ as one of the two [M $-\mathrm{H}$ $\left.-\mathrm{RnCO}_{2} \mathrm{H}-100\right]^{-}$ions. This interference is negligible because the intensity of the $\left[\mathrm{M}-\mathrm{H}-\mathrm{RnCO} \mathrm{CO}_{2} \mathrm{H}-74\right]^{-}$ion is low in

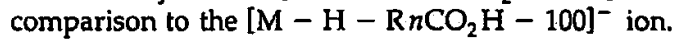



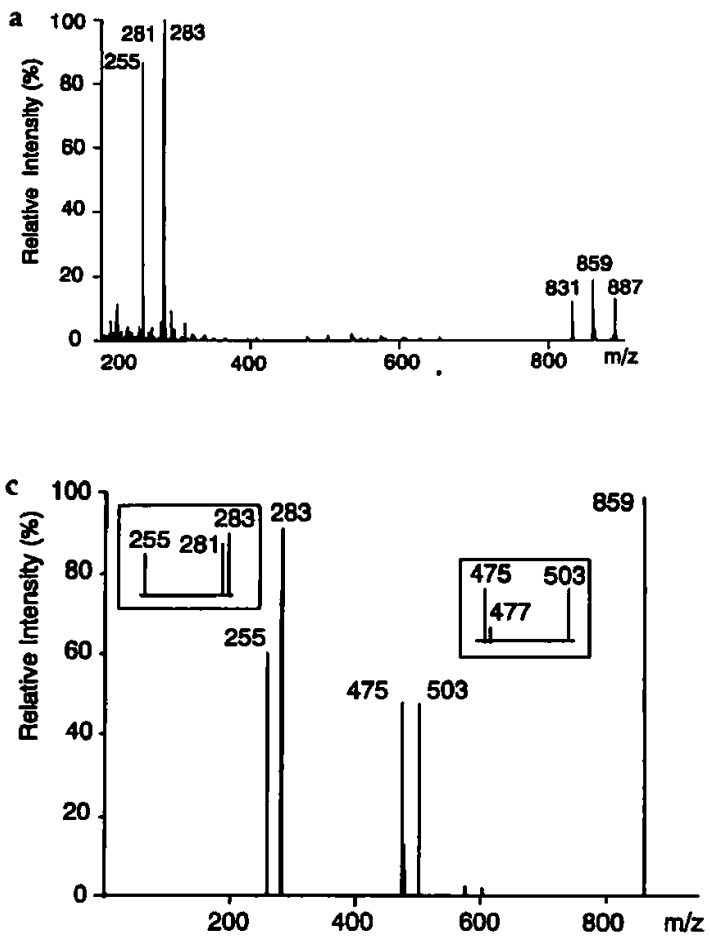
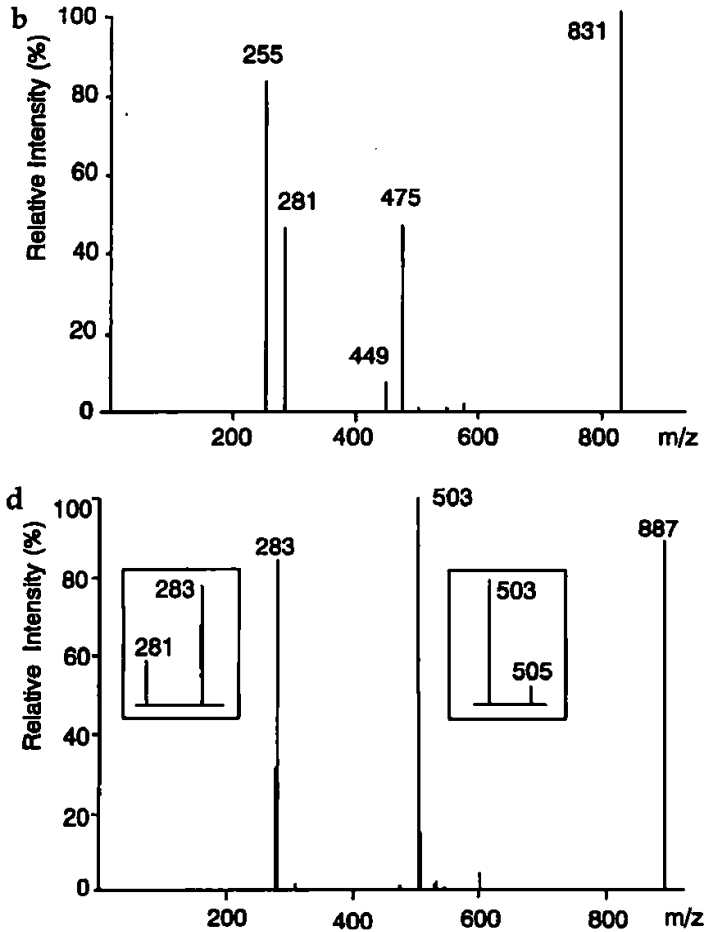

Figure 4. (a) DCI mass spectrum of natural cocoa butter and DCI tandem mass CID fragmentation spectra at $0.5 \mathrm{~V}$ collision offset voltage of $[\mathrm{M}-\mathrm{H}]^{-}$ions at $m / z 831$ (b), 859 (c), and 887 (d).

spectra of POP and PPO, where these ions appear with different intensities. These ketone enolates contain mainly the hydrocarbon chains of the central fatty acid combined with one of the outermost chains. The ketone enolate that results from the condensation between the two outermost fatty acids is also always present, but with a much weaker intensity (about $20 \%$ of the intensity of the main ketone anion). Thus, these fragments allow the clear distinction between the POP and PPO isomers. The same reason as previously can be invoked to explain this sensitivity to the position of the fatty acids for the fragmentation reaction that leads to the ketone enolates. Indeed, as shown in Scheme VI, the expulsion of the ketone enolates that contain the hydrocarbon chains of the central fatty acid combined with one of the outermost chains (Scheme VI, pathway c) requires the formation of a neutral epoxide, which is faster than the neutral oxetane formation necessary for the expulsion of the ketone enolate that results from the condensation between the two outermost fatty acids (Scheme VI, pathway f).

Thus, these fragmentation spectra of the $[\mathrm{M}-\mathrm{H}]^{-}$ ions not only allow the determination of the masses of the contained fatty acids, but also permit distinction
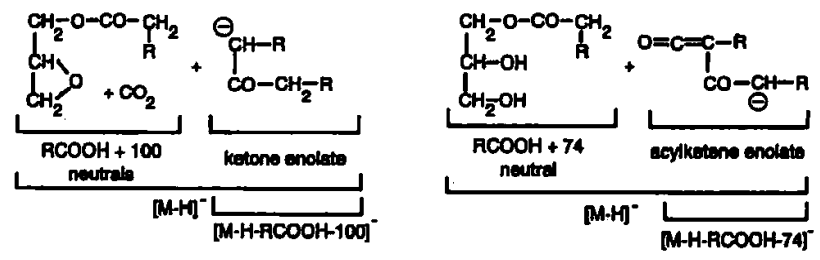

Scheme V between the fatty acids at the primary and secondary positions on the glycerol moiety. Enantiomers cannot be distinguished by this method. The method has been checked by us on 27 commercial triacylglycerols. All the position isomers were correctly assigned, with no exception.

This method can be directly applied to mixtures of triacylglycerols as illustrated by the analysis of a sam-

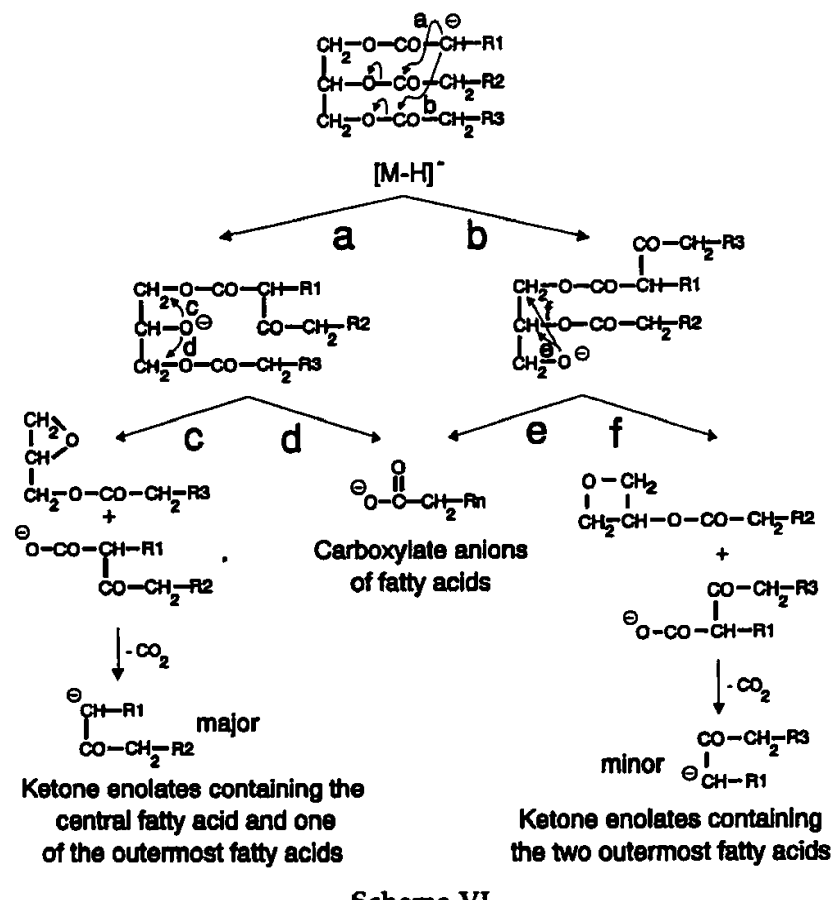

Scheme VI 
Table 4. Masses observed in the various fragment spectra of the three deprotonated anions present in the DCI spectrum of natural cocoa butter ${ }^{\mathrm{a}}$

\begin{tabular}{lccc}
\hline $\mathrm{M}-\mathrm{H}^{-}$ & $\begin{array}{c}\text { Fatty acid carboxylate } \\
\mathrm{RnCOO}\end{array}$ & Ketone enolate & $\begin{array}{c}\text { Triglyceride deduced } \\
\text { structure }\end{array}$ \\
\hline \hline 831 & $255(\mathrm{P}) .281(\mathrm{O})$ & $475\left(\mathrm{~K}_{\mathrm{PO}}\right), 449$ & POP \\
859 & $255(\mathrm{P}) .281(\mathrm{O}), 283(\mathrm{~S})$ & $475\left(\mathrm{~K}_{\mathrm{PO}}\right), 503\left(\mathrm{~K}_{\mathrm{OS}}\right), 477$ & POS or SOP \\
887 & $281(\mathrm{O}) .283(\mathrm{~S})$ & $503\left(\mathrm{~K}_{\mathrm{OS}}\right), 505$ & sos \\
\hline
\end{tabular}

\footnotetext{
${ }^{a}$ Abbreviations: $P=$ palmitic acid, $O=$ oleic acid, $S=$ stearic acid, $K_{p O}=$ ketone that results from the condensation between palmitic and oleic acids, $K_{O S}=$ ketone that results from the condensation between oleic and stearic acids, POP, POS, SOS, position of the corresponding acids in the triglycerides, without assignment of the stereoisomers.
}

ple of natural cocoa butter shown in Figure 4. The results are summarized in Table 4 . The complete structure (i.e., molecular weight of the component fatty acids and primary or secondary position on the glycerol moiety) of the predominant triacylglycerols in this cocoa butter have been correctly assigned.

Another fragment ion always present in the product ion spectra of the triacylglycerols corresponds to the loss of a neutral fatty acid from the $[\mathrm{M}-\mathrm{H}]^{-}$ion. The same fragmentation has been observed for the triglycerides in the positive chemical ionization mass spectra. The proposed mechanism is shown in Scheme VII [18]. Whereas this mechanism can be considered as a quasithermal mechanism that does not involve the charge, it also can be invoked for the formation of the corresponding fragments in the negative ion mode.

\section{Other Fragmentations}

The carboxylate anion always observed in the fragmentation spectra of the studied compounds can be explained by several pathways. Some of these pathways (Scheme VI, pathways $\mathrm{d}$ and $\mathrm{e}$ ) are specific to the triglycerides. The carboxylate anions produced by these routes are in competition with formation of the $\beta$ ketoacid carboxylates that lead to the ketone enolates. To speculate further on these fragmentation pathways without additional information is unjustified.

All the compounds studied also show in their fragmentation spectra, with variable intensity, ions that correspond to the loss of ketenes from the $[\mathrm{M}-\mathrm{H}]^{-}$ ion and their complementary ketene ynolates. These ions can be explained by the fragmentation pathway shown in Scheme VIII.

The enolate of the $\left[\mathrm{M}-\mathrm{H}^{-}\right.$ion undergoes cleavage of the ester bond induced by the negative charge

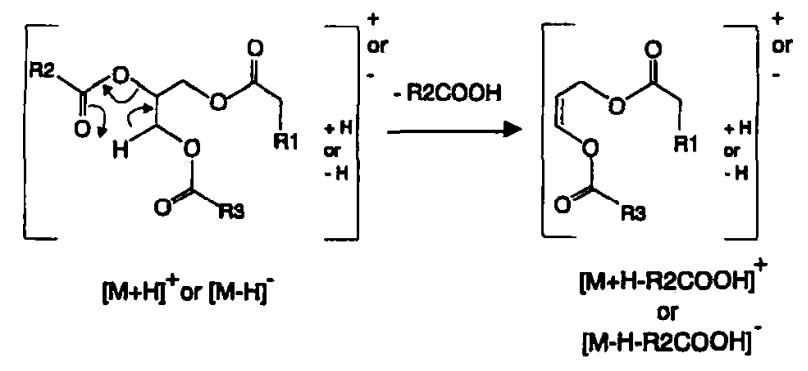

Scheme VII to yield an ion-dipole complex composed of a neutral ketene and an alkoxide ion (Scheme VIII, pathway a). The direct dissociation of this ion-dipole complex (Scheme VIII, pathway c, formula A) competes with an internal proton exchange (Scheme VIII, pathway b) that yields a new complex that consists of an alcohol molecule and the ketene ynolate, which also can dissociate (Scheme VIII, pathway d, formula G). This fragmentation pathway is independent of the rearrangement that results from an internal nucleophilic substitution described in the foregoing text.

\section{Conclusions}

The main result of this study is to show that 1,2 or 1,3 diol esters, under low energy CID, undergo a rearrangement that results from an internal nucleophilic substitution similar to an intramolecular Claisen condensation. From this intermediate, either the enolate of the corresponding ketone is observed or, after additional intramolecular proton transfers, acylketenes enolates or ynolates are formed.

This same rearrangement also occurs in triglycerides, but the fate of the resultant intermediate is mostly the formation of the corresponding ketone enolate, and the subsequent proton transfer is sterically
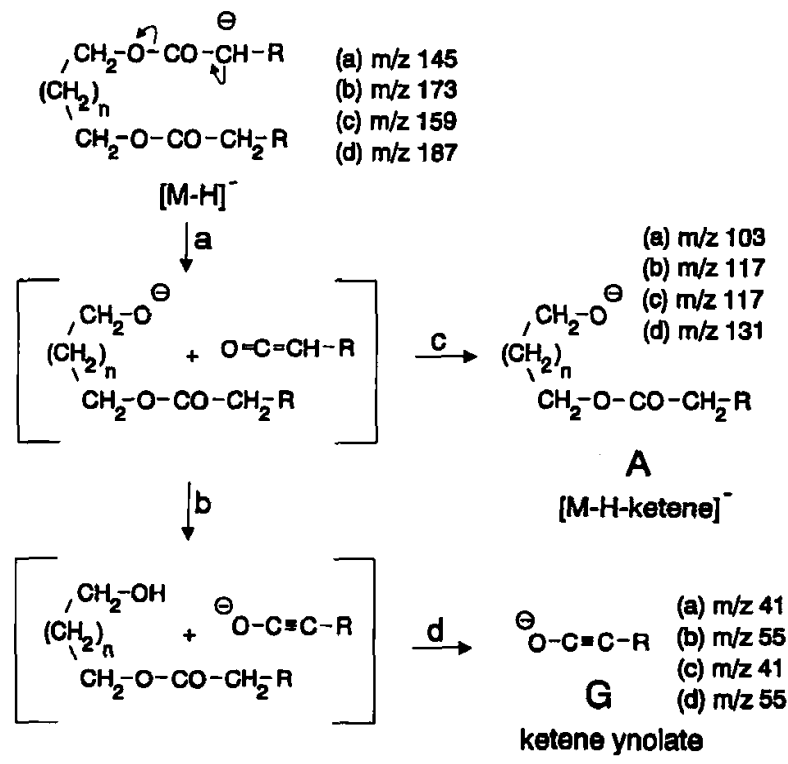

Scheme VIII 
hindered. This mechanism explains the structure of fragments already known to be useful in position elucidation.

\section{References}

1. de Hoffmann, E.; Charette, J.; Stroobant, V. Spectrométrie de Masse; Masson: Paris, 1994.

2. Harrison, A. G. Chemical Ionization Mass Spectrometry; CRC Press: Boca Raton, FL, 1983; p 28 and references therein.

3. Bowie, J. H. Mass Spectrom. Rev. 1990, 9, 349-379.

4. Bowie, J. H. In Experimental Mass Spectrometry; Russell, D. H., Ed.; Plenum Press: New York, 1994; pp 1-34.

5. de Hoffmann, E.; Rozenberg, R.; Deffence, E.; Stroobant, V. Proceedings of the 41th ASMS Conference on Mass Spectrometry and Allied Topics; San Francisco, CA, 1993; p 858.

6. Kallio, H.; Currie, G. Lipids 1993, 28, 207-215.

7. Vogel, A. I. Practical Organic Chemistry, 3rd ed.; Longmans: London, 1962; p 383.
8. de Hoffmann, E.; Auriel, M. Org. Mass Spectrom. 1989, 24, 748-758.

9. Bartmess, J. E.; Hays, R. L.; Caldwell, G. I. Am. Chem. Soc. 1981, 103, 1338-1344.

10. Raftery, M. J.; Bowie, J. H. Org. Mass Spectrom. 1988, 23, 719-722.

11. Burinsky, D. J.; Cooks, R. G. J. Org. Chem. 1982, 47, 4864-4869.

12. Dua, S.; Pollnitz, A. P.; Bowie, J. H. J. Chem. Soc. Perkin Trans. 2 1993, 2235-2241.

13. Eliel, E. L. In Steric Effects in Organic Chemistry; Newman, M. S., Ed.; Wiley: New York, 1956; p 61.

14. Lias, S. G.; Bartmess, J. E.; Liebman, J. F.; Holmes, J. L.; Levin, R. D.; Mallard, G. J. Phys. Chem. Ref. Datn 1988, 17, Suppl. 1.

15. Fournier, F.; Remaud, B.; Blasco, T.; Tabet, J.-C. I. Am. Soc. Mass Spectrom. 1993, 4, 343-351.

16. Grabowskii, J. J.; Cheng, X. J. J. Am. Chem. Soc. 1989, 111, 3106.

17. McAdoo, D. J. Mass Spectrom. Rev. 1988, 7, 363-393.

18. Murphy, R. C. Mass Spectrometry of Lipids; Plenum Press: New York, 1993; p 197. 